\title{
Rapid groundwater potential mapping in humanitarian contexts: improving borehole implementation in basement environments
}

\author{
Cyrille Scherrer $^{1}$ (D) $\cdot$ Ryan Schweitzer ${ }^{2} \cdot$ Marc-André Bünzli $^{3} \cdot$ Ellen Milnes $^{1,2,3}$
}

Received: 24 November 2020 / Accepted: 21 April 2021 / Published online: 16 June 2021

(C) The Author(s) 2021

\begin{abstract}
Emergency responses in humanitarian contexts require rapid set-up of water supply. Boreholes are often drilled where the needs are highest and not where hydrogeological conditions are most favourable. The Rapid Groundwater Potential Mapping (RGWPM) methodology was therefore developed as a practical tool to support borehole siting when time is critical, allowing strategic planning of geophysical campaigns. RGWPM is based on the combined analysis of satellite images, digital elevation models and geological maps, obtained through spatial overlay of the two main hydrogeological variables controlling groundwater potential: water availability (WA) and reservoir capacity (RC). The WA associates hydrogeomorphological features to groundwater dynamic processes, while the RC reflects estimates of the hydraulic conductivity. RGWPM maps are produced through an overlay of WA and RC with the overall groundwater potential (GWP) characterized as 'very low', 'low', 'medium', and 'high', with each zone associated to a specific water supply option. The first RGWPM map was elaborated during a drilling campaign in Northern Uganda. The average yield for the eight boreholes sited 'with' RGWPM was $35 \mathrm{~m}^{3} / \mathrm{h}$ versus $3 \mathrm{~m}^{3} / \mathrm{h}$ for the 92 preexisting boreholes that were sited 'without' RGWPM. Statistical comparison of the classified yields of all hundred boreholes with the RGWPM predicted-yield ranges revealed a good correlation for the 'low' GWP unit, highlighting areas where well siting for motorised systems should be avoided. A rather poor correlation of 33\% was found for the 'medium' GWP unit, believed to be artificially induced by the numerous hand pumps (low yields) located in potentially higher yielding areas.
\end{abstract}

Keywords Crystalline rocks · Groundwater exploration · Groundwater potential mapping $\cdot$ Hydrogeomorphology $\cdot$ Water supply

\section{Introduction: a growing need for motorised water supply systems}

Globally, the number and duration of violent conflicts and forced displacements has increased significantly, from 42.7 million in 2007 to 79.5 million in 2019 (UNHCR 2020), resulting in a rising number of people in refugee camps and settlements. Displaced persons are often hosted in areas with limited water supply infrastructure, where water scarcity and climate change are critical factors already affecting the host

Cyrille Scherrer

cyrille.scherrer@unine.ch

1 The Centre for Hydrogeology and Geothermics of University of Neuchâtel, Rue Emile-Argand 11, 2000 Neuchâtel, Switzerland

2 United Nations High Commissioner for Refugees, Rue de Montbrillant 94, 1201 Genève, Switzerland

3 Swiss Humanitarian Aid, Swiss Agency for Development and Cooperation, Effingerstrasse 27, 3003 Bern, Switzerland population (WWAP 2019). To meet the increasing water demand in emergency contexts, it is key to quickly assess all possible water sources and plan sustainable water supply options in order to rapidly transition away from acute emergency phase water supply, often done with costly, unreliable and logistically challenging water trucking. In any humanitarian response, the choice of the water supply option in the early emergency phase is crucial, as it will impact the mid and longterm costs as well as issues related to water resource management.

When water demand dramatically increases due to high numbers of newly displaced people, hand pump water supply is often not the most cost-effective option. Hand pump water supply is not well suited for humanitarian situations with large displaced populations or where there is high population density - for example, over 16,000 hand pumps were drilled within only $10 \mathrm{~km}^{2}$ in the recent Rohingya refugee crisis in Bangladesh between 2017 and 2018. Hand pumps have logistical and economic advantages, such as independence from external energy sources and relatively low capital, operation 
and maintenance costs. However, there are also considerable disadvantages to hand pumps-for example, their extraction rate is limited to $0.5 \mathrm{~m}^{3} / \mathrm{h}$, water treatment is difficult, and the time required for collection and transport disproportionally affects girls and women (Hutton et al. 2004). Water collection reinforces time poverty, disempowers women, reduces school attendance for girls, and exposes women and girls to sexual and gender-based violence and injuries associated with water carrying. With the general trend in humanitarian contexts moving towards sustainability-focused water resource management through motorized-solar driven pumping systems (e.g. Global Solar Water Initiative, UNHCR Clean Energy Challenge (UNHCR 2021a)), the target aquifer productivity has increased by an order of magnitude, from $0.5 \mathrm{~m}^{3} / \mathrm{h}$ for hand pumps to over $5 \mathrm{~m}^{3} / \mathrm{h}$ for motorised systems.

Target aquifer productivity is central for measuring "drilling success rates", a widespread but poorly defined notion, mostly used to define if yields are sufficient to support hand pumps. It is often understood as binary, with a "dry borehole" declared for yields below $0.5 \mathrm{~m}^{3} / \mathrm{h}$, while yields above this threshold are considered "successful". If this same binary "drilling success rate" definition were to be applied to motorized systems, which require yields exceeding $5 \mathrm{~m}^{3} / \mathrm{h}$, then all boreholes yielding less than $5 \mathrm{~m}^{3} / \mathrm{h}$ would have to be declared as "dry boreholes", although they may be equipped with hand pumps; therefore, the "drilling success" notion requires a more nuanced definition, which relates target aquifer productivity to yield ranges and to different water supply options. In essence, this means that the binary spatial "drilling success rate" distributions ("dry" versus "successful") for hand pumps and motorized systems, respectively are different. The spatial distribution of "successful" motorized systems, targeting yields exceeding $5 \mathrm{~m}^{3} / \mathrm{h}$ is of course contained within the spatial distribution of "successful" hand pumps, since hand pumps will also function in areas yielding more than $5 \mathrm{~m}^{3} / \mathrm{h}$. On the contrary, motorized systems cannot be successfully implemented in areas yielding less than $5 \mathrm{~m}^{3} / \mathrm{h}$, while hand pumps can. As the siting process for motorised water supply boreholes requires identification of highly productive locations, it is crucial that such areas are rapidly identified on a scale that is relevant to water supply and distribution, typically within a radius of $10 \mathrm{~km}$ around the zones where water is needed and on a scale which allows planning of high-resolution geophysical campaigns.

The rapid groundwater potential mapping (RGWPM) methodology presented herein does not only seek to identify highly productive zones, but aims at complete mapping of areas of interest, identifying the likelihood of where and which water supply option is most adapted. The need for a tool for the rapid spatial assessment of "yield range probabilities" associated to different water supply options emerged following a major refugee influx from South Sudan into Northern Uganda in 2017. During the acute emergency phase in 2017 water was supplied to approximately 400,000 people by as many as 630 trucks delivering $6,547 \mathrm{~m}^{3} /$ day, leading to extremely high costs and logistical challenges (UNHCR 2017a). A drilling campaign in 2018, involving 52 boreholes for solarised water supply systems, was part of the long-term strategy for sustainable water supply. A pilot RGWPM was developed to guide the geophysical prospection for this drilling campaign and proved to be highly effective. The results of the RGWPM in Uganda were encouraging and suggested that the approach may be up-scaled and widely applicable within similar types of geological conditions found in Sub-Saharan Africa.

This paper reviews the literature on groundwater potential mapping approaches, putting the RGWPM methodology in context before focussing on the specific conceptual framework. Then, the Northern Ugandan case study is presented with the step-by-step description of the technical aspects of RGWPM. Finally, retrieved field data from Northern Uganda is used to quantify the impact of RGWPM, by comparing borehole yields of wells sited 'with' and 'without' RGWPM. The case study not only revealed substantial increase in cumulative yields for wells sited with RGWPM but also, and perhaps more importantly, high-lighted the usefulness of such maps in delimiting areas where no effort should go into well siting for motorised systems.

\section{Embedding rapid groundwater potential mapping in the landscape of groundwater potential mapping}

A recent review of groundwater potential mapping published by Díaz-Alcaide and Martínez-Santos (2019) concluded that there is no universal definition of groundwater potential and standardised method for developing maps, or commonly accepted set of units to measure the outcomes. Their review revealed that some groundwater potential maps provide an indication of the variations in groundwater storage across a given region, while other studies interpret the groundwater potential as a measure of how likely groundwater is to be found or where the highest yields may take place. The review concluded that the objective of most groundwater potential studies is to identify the optimal zone(s) for groundwater development, which is also the case for the RGWPM approach presented herein.

Díaz-Alcaide and Martínez-Santos (2019) further argued that 'potential' is related to a 'probability of something occurring' and defined it as a spatially distributed best estimate of the physical capacity of the terrain to yield enough groundwater for a given use based on a series of indirect indicators. Their analysis of 200 studies identified the following key parameters: lithology (geology), geomorphology, soil, land use, topography, lineaments, drainage and slope related variables, 
rainfall and groundwater recharge. RGWPM also directly or indirectly uses these key parameters.

Another characteristic of groundwater potential mapping is that variables are classified and zoned in a multi-criteria decision framework (Teixeira et al. 2015), followed by different map algebraic approaches (Ettazarini 2007; Elewa and Qaddah 2011), leading to a classified likelihood of attaining a target value (e.g. sufficient yield for hand pump or motorized water supply). Díaz-Alcaide and Martínez-Santos (2019) concluded that for optimal results, groundwater mapping must be used as a tool to inform fieldwork and that remote sensing techniques in groundwater exploration have an enormous potential.

The major drawback of the groundwater potential mapping approaches evaluated by Diaz-Alcaide and Martinez-Santos (2019) is the lack of validation of the maps with field data. Overall, groundwater potential maps should be used to optimise field work, rather than as a low-cost substitute for localscale surveys (Abdalla 2012; Mandal et al. 2016). The RGWPM methodology presented hereafter is fully aligned with these conclusions, since the objective is to inform local geophysical field investigations for borehole siting. Considering the taxonomy of groundwater potential mapping approaches described by Diaz-Alcaide and Martinez-Santos (2019), RGWPM generated by the methodology presented herein are a priori high-resolution $\left(20-100 \mathrm{~km}^{2}\right)$ and nearsurface groundwater potential maps (depths reaching 100 $150 \mathrm{~m}$ ) with no or very little ground-truth data. The additional and unique characteristic of RGWPM is the short amount of time required to produce the maps - just days or weeks.

\section{Conceptual framework of RGWPM}

The conceptual framework of RGWPM directly links to the overarching goals of groundwater potential maps described in the preceding, aiming at identifying different groundwater potential zones by map overlay of different groundwater relevant variables. In the RGWPM methodology, two spatial variables are defined: water availability (WA) and reservoir capacity (RC). The WA variable reflects the spatial distribution of groundwater recharge and discharge processes, while the RC variable is linked to hydraulic conductivity.

The overall objective of RGWPM is to identify which water supply options are most appropriate in a given area by mapping the two RGWPM variables and associating them to four 'yield classes' which are correlated to water supply options: (1) the 'very low' class for expected well yields smaller than $0.5 \mathrm{~m}^{3} / \mathrm{h}$, where no groundwater supply option (i.e. not even hand pumps) should be envisaged, (2) the 'low' class for yield ranging between 0.5 and $5 \mathrm{~m}^{3} / \mathrm{h}$, typical for hand pump water supply (e.g. Chilton and Foster 1995; Houston 1992), followed by (3) the 'medium' class, covering the range between 5 and $50 \mathrm{~m}^{3} / \mathrm{h}$, typical for small motorised systems and finally (4) the 'high' class for yields exceeding $>50 \mathrm{~m}^{3} / \mathrm{h}$, typical for large motorised systems. The choice of the yield ranges roughly corresponds to the ranges of typical submersible pump sizes required, which in turn govern the drilling diameter. Since drilling diameter has a major cost implication but will determine which maximum yield can be withdrawn, the water supply option has to be considered from the very start. Hence, the main objective of these yield ranges is to highlight the four orders of magnitude which are covered by the different water supply options, rather than pinpointing exact yield ranges. The main objective of RGWPM is to identify the most appropriate water supply option for a given location and NOT to precisely predict the yield of a specific well. The following section will explain the mapping process which relies on a qualitative assessment and spatial overlay of the variables, leading to probability distributions and not to precise predictions.

\section{Water availability}

In the RGWPM approach, the water availability (WA) is linked to groundwater flow and landscape features. The vast majority of landscapes result from physical and bio-chemical processes occurring in response to the interaction between the solid earth and the biosphere with surface water and groundwater. The discipline which addresses this interaction is hydrogeomorphology (e.g. Scheidegger 1973; Sidle and Onda 2004), which seeks to identify how different forms of water transform different landscapes. Landscapes with their specific geomorphic features can be understood as a snapshot of the cumulative interaction between the solid earth and the main fractions into which rainfall is transformed: surface runoff and infiltration, with infiltration subdivided into evapotranspiration and groundwater recharge. Hence, specific landscape features reveal both surface and groundwater dynamic processes. Scientists interested in the understanding of surface-water systems have long recognized that drainage basins are a fundamental hydrologic feature, controlled to a large extent by their geologic framework and climatic setting (Horton 1945; Leopold et al. 1964; Chorley et al. 1984). Groundwater flow is also governed by the geologic framework, climatic setting (Tóth 1963; Freeze and Witherspoon 1967) and interaction with surface waters, with aquifer systems considered as fundamental hydrogeologic units (Meinzer 1923; Heath 1984).

Surface runoff leaves a fingerprint in the landscape by physical erosion, sediment transport and deposition, while infiltration contributes to landscape features through (bio-)chemical erosion such as weathering. For a given rainfall intensity, the proportion contributing to either physical or chemical erosion processes is related to the hydraulic properties of the earth material. A lower permeability of the substratum 
combined with a higher rainfall will lead to a higher physical erosion as compared to chemical weathering and vice versa.

The conceptual framework for WA involves analysing the landscape for specific hydrogeomorphological features related to such physical and chemical interaction between water and the solid earth in order to extract relevant indicators of groundwater dynamic processes (i.e. groundwater recharge and discharge). For the purpose of the WA conceptualisation, Winter's (2001) definition of three fundamental hydrologic landscape units, as shown on the left in Fig. 1, is very useful. This classification subdivides landscapes into three building blocks, i.e. upland, slope and lowland, each of which is related to the geologic framework and the climatic setting. These landscape building blocks are mirrored on the right in Fig. 1 into the RGWPM conceptualisation of the hydrologic system consisting of surface runoff, groundwater flow and interaction with atmospheric and surface water.

The upland unit as defined by Winter (2001) has no geomorphological features indicative of physical erosion and is defined by the area situated above channel initiation points. This area is characterised by diffuse groundwater recharge and divergence of groundwater flow in the RGWPM approach (Fig. 1), resulting in the absence of axial groundwater flow. In the RGWPM terminology, which presents groundwater availability within a landscape on a relative scale, this unit is associated with a low WA, as shown on the bottom in Fig. 1. In terms of water supply class, this area can at best support hand pump water supply. No groundwater supply option (very low WA class) can be expected in areas within the upland unit, where bedrock is exposed or where regolithic (weathered surface layer) thickness is thin, being areas highly unfavourable for diffuse groundwater recharge.

Within the Winter (2001) slope unit (Fig. 1), runoff is conveyed within the drainage systems developed through physical erosion, with sediment transport taking place. The slope unit is associated with concentrated groundwater recharge along the drainage systems and diffuse recharge on the lateral slopes combined with axial groundwater flow from the upland unit (right side Fig. 1). The main groundwater relevant geomorphological features characterising the slope unit are ephemeral streams, typical of groundwater being disconnected from surface-water bodies. In the RGWPM terminology for WA, this landscape unit is subdivided into medium and 'slope' WA (bottom Fig. 1). The 'medium WA', associated with the potential for small motorised systems, is defined by the existence of both concentrated recharge along the drainage network and axial groundwater flow from the upland unit. The 'slope WA' class within the slope unit, however, is only associated with diffuse recharge. Hence, the slope WA class, although associated with low WA, and thus with the hand pump water supply option, distinguishes itself from the 'low WA' class of the upland unit by the presence of axial groundwater flow coming from the upland, rendering these areas

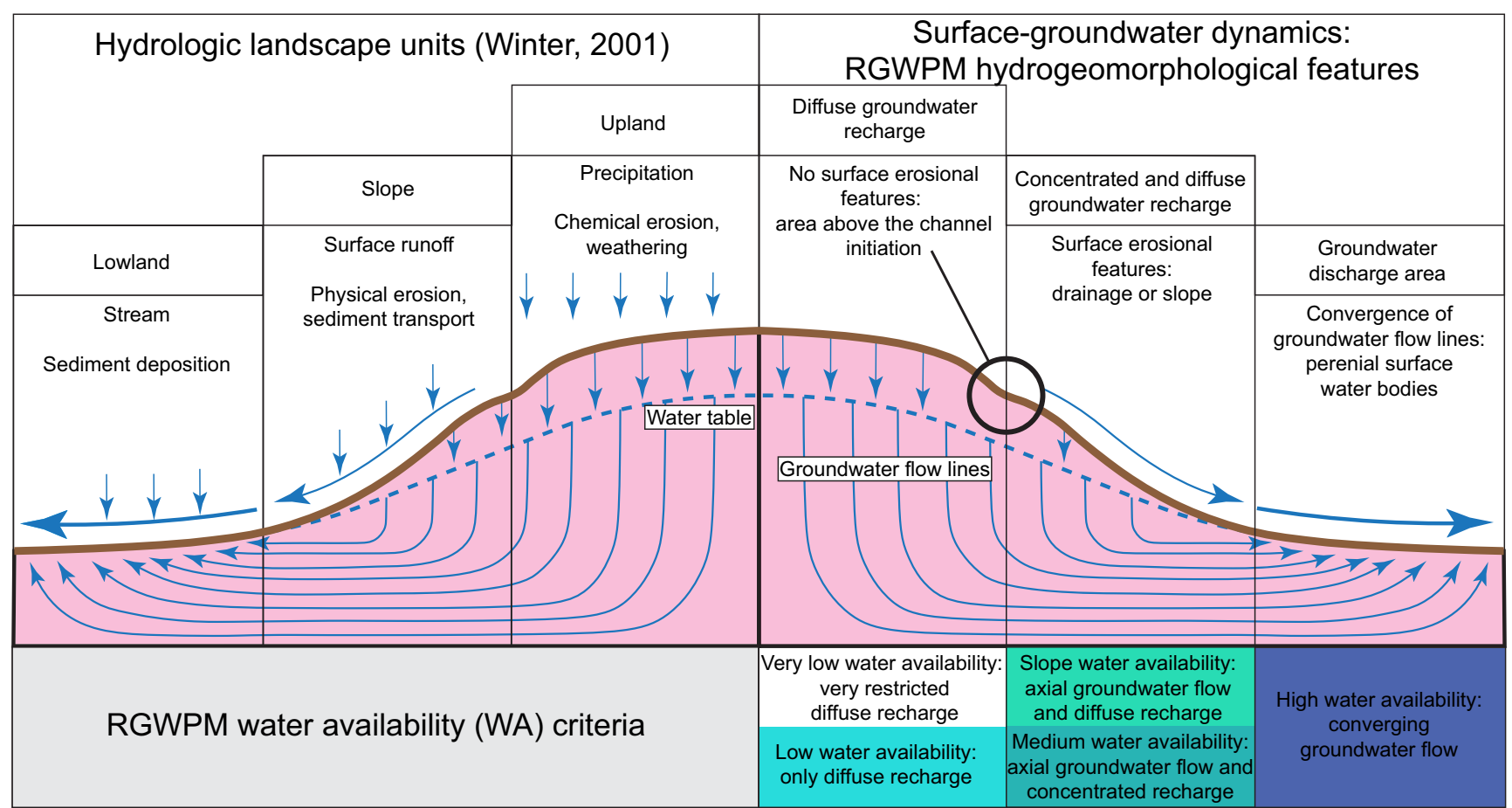

Fig. 1 The left side of the figure shows a conceptual illustration of the landscape subdivision defined in Winter's (2001) fundamental hydrological units, with the upland being separated from the lowland by the valley or slope-side. The right side shows analogue units defined in the
RGWPM methodology with the associated hydrogeomorphological features and groundwater relevant processes. Bottom: definition of water availability (WA) criteria in the RGWPM space 
more favourable with regard to groundwater availability than the upland.

Winter's (2001) lowland unit distinctive geomorphological characteristics include perennial surface-water bodies and sediment deposition. In terms of WA in the RGWPM space, perennial surface-water bodies occur where aquifers are connected to surface-water bodies, which in terms of regional groundwater flow only takes place in discharge areas where groundwater flow converges, as illustrated in Fig. 1. These areas are associated with the 'high WA' class, as shown on the bottom in Fig. 1, designating areas, where, from a groundwater availability perspective, large motorised systems can potentially occur, depending on the hydraulic properties of the subsurface, i.e. reservoir capacity.

\section{Reservoir capacity}

The second RGWPM variable is the reservoir capacity (RC), which is a relative measure of hydraulic conductivity, reflecting how easily groundwater is estimated to circulate in the subsurface. Estimating hydraulic properties on a regional scale is a difficult task. The authors fully acknowledge that the approach described hereafter is simplistic; however, as previously mentioned, the objective of RGWPM does not seek to map or predict yields of specific wells, but rather estimate probabilities. For this reason, the variable name has been adapted to reservoir capacity (RC), in order to avoid any direct linkage to hydraulic conductivity. In the RGWPM approach, $\mathrm{RC}$ classification is done by assigning hydraulic conductivities extracted from literature (e.g. Freeze and Cherry 1979) to lithologies and to tectonic features such as faults and fracture zones. The lithologies are identified from existing geological maps, while the tectonic features are identified using high resolution satellite images such as Bing or by combining bands from LandSat images (e.g. Sikakwe 2020).

Just as for the WA, RC is divided into four classes (very low, low, medium and high), which are associated with yield classes and the most likely water supply options. To obtain estimated well yields, the estimated hydraulic conductivity of a lithology is introduced into the analytical solution of Dupuit for confined aquifers (Dupuit 1857), making the assumptions that aquifer thickness is $60 \mathrm{~m}$, with a drawdown of $20 \mathrm{~m}$, the borehole radius is $4 "(10 \mathrm{~cm})$ and the average radius of influence is $15 \mathrm{~m}$. These assumptions correspond to widely observed average values encountered in boreholes drilled in fractured aquifers in the Sub-Sahara. This approach produces four hydraulic conductivity ranges corresponding to the four RC classes: (1) estimated hydraulic conductivities $K$ smaller than $10^{-7} \mathrm{~m} / \mathrm{s}$ assigned to the very low RC class, (2) with $K$ ranging between $10^{-7}$ and $10^{-6} \mathrm{~m} / \mathrm{s}$ assigned to the low class, followed by (3) the medium class for estimates of $K$ ranging between $10^{-6}$ and $10^{-5} \mathrm{~m} / \mathrm{s}$ and (4) with the high class for all estimates of $K$ exceeding $10^{-5} \mathrm{~m} / \mathrm{s}$. Table 1 shows these classes and the associated water supply options.

Literature suggests that hydraulic conductivity in fault zones may increase as much as $2-3$ orders of magnitude from the bulk rock hydraulic conductivity, depending on fracture density and connectivity (e.g. Evans et al. 1997; Bense et al. 2013). To address this challenge in the RGWPM approach, the hydraulic conductivity estimation made for fault zones is increased by one order of magnitude as compared to the surrounding host rock. This implies a shift into the next higher RC class, according to Table 1.

\section{RGWPM: spatial overlay of WA and RC}

The spatial overlay of WA and the RC determines the groundwater potential (GWP) of the RGWPM, with the lower class of the two variables dictating the GWP. Figure 2 shows the RGWPM matrix with the RC classes on the vertical axis and the WA classes on the horizontal axis. The mapping criteria of the two variables, as described in the previous section are summarised in the matrix and five groundwater potentials (GWP) are distinguished: very low, low, slope, medium and high which in turn are associated to the different water supply options, also mentioned in the diagonal of the matrix in Fig. 2. The slope GWP, although very similar to the low, due to diffuse groundwater recharge only, is distinguished as a separate unit, due to the higher WA derived from axial groundwater flow, as discussed in section 'Water availability'.

The matrix reveals that the lower of the two variables will determine the potential, e.g. low WA combined with high RC will lead to a low groundwater potential and similarly for any combination of the two variables. Hence, the probability of high groundwater potential is restricted to zones with both high WA and high $\mathrm{RC}$, explaining why these areas are the least frequently encountered.

With the mapping criteria for WA being easier to implement than for RC, it is useful to start with this variable. This allows reducing the mapped area of the RC by excluding the very low WA area, because whatever the $\mathrm{RC}$ in this area is, the associated GWP will be limited by the very low WA variable. Similarly, the mapping area for RC can be further reduced by excluding the low and slope WA areas for RC mapping, unless hydraulic conductivity estimates are lower than $10^{-7} \mathrm{~m} / \mathrm{s}$, i.e. very low.

\section{Limitations and validity of conceptual framework}

The RGWPM conceptual framework, as described previously, is only valid in topography-driven groundwater settings, in which landscape features can be related to groundwater dynamics. Haitjema and Mitchell-Bruke (2005) identified the conditions for topography-driven groundwater flow systems on a regional scale and therefore neglecting the process of 
Table 1 Reservoir capacity classification for estimated hydraulic conductivity ranges and estimated yield ranges, as well as associated water supply options

\begin{tabular}{llll}
\hline $\begin{array}{l}\text { Reservoir capacity } \\
(\mathrm{RC})\end{array}$ & $\begin{array}{l}\text { Hydraulic conductivity } \\
K(\mathrm{~m} / \mathrm{s})\end{array}$ & $\begin{array}{l}\text { Estimated yield range } \\
\left(\mathrm{m}^{3} / \mathrm{h}\right)\end{array}$ & Associated water supply option \\
\hline High & $>10^{-5}$ & $>50$ & Large motorised systems \\
Medium & $10^{-6}-10^{-5}$ & $5-50$ & Small motorised systems \\
Low & $10^{-7}-10^{-6}$ & $0.5-5$ & Hand pumps \\
Very low & $<10^{-7}$ & $<0.5$ & $\begin{array}{l}\text { Groundwater use may not be } \\
\text { appropriate }\end{array}$ \\
\hline
\end{tabular}

interflow, based on analytical Forchheimer-Dupuit assessments (Dupuit 1863; Forchheimer 1986), in which several dimensionless ratios were used. The ratio between groundwater recharge $(R)$ and hydraulic conductivity $(K)$ relates to the geological and climatic framework. Haitjema and MitchellBruke (2005) concluded that topography-controlled water tables are most likely to occur in low-permeability earth materials such as in the Precambrian basement shield covering vast areas of the Sub-Saharan belt. This vast basement complex is characterised by a typical regolithic weathering profile (e.g. Taylor and Howard 2000) leading to continuous topographydriven small groundwater bodies within the saprolite forming the interface between the weathering front and the fresh bedrock, overlying deeper fracture zones. Very often, the weathering front and interface with the fresh bedrock is situated at depths of 20-40 m below the topographic surface (Wright 1992).

A second limitation of RGWPM is related to its nearsurface character. In areas where geological conditions within the first $150 \mathrm{~m}$ below the surface are highly heterogeneous, the projection of surface lithological information from geological maps cannot be done and therefore estimates for the RC variable may not be meaningful.
Nearly two thirds of all humanitarian camps and settlements located in Sub-Saharan Africa are in the geologic basement complex, for which the conceptual framework is valid. Therefore, there is considerable potential for applying the RGWPM methodology within humanitarian contexts. In the next section, the application of the RGWPM methodology in Northern Uganda is described, first setting the scene of the general context of the case study area, before discussing step-by-step the details of the construction of the map layers.

\section{RGWPM of the Bidibidi refugee settlements (northern Ugandan)}

The Bidibidi refugee settlements are located in Northern Uganda in the district of Yumbe, close to South Sudan and the Democratic Republic of Congo (Fig. 3). These settlements hosted over 280,000 refugees in 2017, mostly from South Sudan, making it one of the largest refugee settlements in the world (UNHCR 2017b). The settlements are situated in a semiarid environment, or, more specifically, in a Tropical Savannah climate (Beck et al. 2018). Northern Uganda has a wet season from March to November and a dry season from

\begin{tabular}{|c|c|c|c|c|c|c|}
\hline & \multicolumn{5}{|c|}{ Water availability (WA) i.e gw. recharge or discharge } \\
\hline & & $\begin{array}{l}\text { Very low: } \\
\text { restricted diffuse } \\
\text { recharge }\end{array}$ & $\begin{array}{l}\text { Low: } \\
\text { only diffuse } \\
\text { recharge }\end{array}$ & $\begin{array}{l}\text { Slope: } \\
\text { axial gw. flow } \\
\text { and diffuse } \\
\text { recharge }\end{array}$ & $\begin{array}{c}\text { Medium: } \\
\text { axial gw. flow } \\
\text { and concentrated } \\
\text { recharge }\end{array}$ & $\begin{array}{l}\text { High: } \\
\text { converging } \\
\text { gw. flow }\end{array}$ \\
\hline \multirow{4}{*}{ 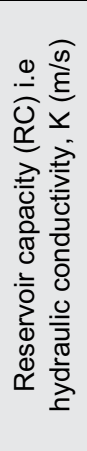 } & $\begin{array}{l}\text { Very low: } \\
\mathrm{K} \approx<10^{-7}\end{array}$ & $\begin{array}{c}\text { Very low GWP: } \\
\text { Surf. water option } \\
\quad<0.5 \mathrm{~m}^{3} / \mathrm{h} \\
\end{array}$ & Very low GWP & Very low GWP & Very low GWP & Very low GWP \\
\hline & $\begin{array}{c}\text { Low: } \\
\mathrm{K} \approx 10^{-7}-10^{-6}\end{array}$ & Very low GWP & $\begin{array}{l}\text { Low GWP: } \\
\text { Hand pump } \\
\approx 0.5-<5 \mathrm{~m}^{3} / \mathrm{h} \\
\end{array}$ & Low GWP & Low GWP & Low GWP \\
\hline & $\begin{array}{c}\text { Medium: } \\
\mathrm{K} \approx 10^{-6}-10^{-5}\end{array}$ & Very low GWP & Low GWP & $\begin{array}{l}\text { Slope GWP: } \\
\text { Hand pump } \\
\approx 0.5-<5 \mathrm{~m}^{3} / \mathrm{h} \\
\end{array}$ & $\begin{array}{l}\text { Medium GWP: } \\
\text { Small moto. } \\
\approx 5-<50 \mathrm{~m}^{3} / \mathrm{h} \\
\end{array}$ & Medium GWP \\
\hline & $\begin{array}{c}\text { High: } \\
\mathrm{K} \approx>10^{-5}\end{array}$ & Very low GWP & Low GWP & Slope GWP & Medium GWP & $\begin{array}{l}\text { High GWP: } \\
\text { Large moto. } \\
\approx>50 \mathrm{~m}^{3} / \mathrm{h}\end{array}$ \\
\hline
\end{tabular}

Fig. 2 RGWPM matrix showing the mapping criteria for the overlay of the two variables, water availability (WA) and reservoir capacity (RC), with the associated groundwater potential (GWP) and associated dominant water supply options 
December to February. The precipitation in this region is between 1,200 and $1,400 \mathrm{~mm} /$ year, while evapotranspiration is around $900-1,000 \mathrm{~mm} /$ year (e.g. Kyatengerwa et al. 2020). Like most of Sub-Saharan Africa, the Bidibidi settlements in Northern Uganda are located on the basement, i.e. the Precambrian shield (e.g. Wyns et al. 2015), consisting of igneous or metamorphic rocks, with a regolithic weathered carapace (e.g. Taylor and Howard 2000). The geological map (bottom right of Fig. 3) shows that the Bidibidi settlements are located on the Mirian gneiss complex which are flaggy gneisses affected by the Mirian tectonics in West Nile (DGSM 2004). The western branch of the East African rift terminates at the height of the settlements of Bidibidi (Purcell 2018) and induced large regional faults, shown as red lines in the tectonic sketch in Fig. 3 (Thiéblemont et al. 2016). The RGWPM developed for the Bidibidi settlement area, as shown in Fig. 3 , is located on the left margin of the rift (Horst) along regional NE-SW normal fault systems, which can be followed over tens of kilometres. These normal faults induced a graben along the east where the Nile flows to South Sudan, filled with sediments. Fresh bedrock crops out only rarely in the Bidibidi area, since most of the bedrock is covered by typical regolith resulting from chemical weathering.

In the early stages of a humanitarian crisis, humanitarian actors may opt to drill boreholes close to people in need of water and in the places most easily accessible to drilling rigs, without siting boreholes based on hydrogeological criteria. Since the beginning of the South Sudanese refugee influx to Uganda in 2016, hundreds of the boreholes that were drilled failed to achieve sufficient yields to warrant the installation of motorized pumps, since only a few humanitarian actors used hydrogeological investigations to site boreholes. After numerous "dry boreholes" had been drilled, the need for strategic well siting became evident. In 2018 UNHCR carried out a major drilling campaign in refugee settlements. It was during this drilling campaign that RGWPM was first field tested (Fig. 3). Geophysical campaigns were planned using this RGWPM and 52 wells were drilled, with 8 of them in Bidibidi (blue circles with black dots in Fig. 3), in an area where already 176 wells had been drilled by numerous different humanitarian actors in 2016-2017, without RGWPM.

Figure 3 shows the map resulting from the RGWPM procedure for the district of Yumbe (Northern Uganda). The detailed methodology which led to this map will be discussed step-by-step in the next section. The map reveals four groundwater potential (GWP) zones: very low shown in white, low in light green, the slope GWP in green and the medium groundwater potential area in dark green. In the whole area, no high groundwater potential exists. In Fig. 3, the small circles represent boreholes, which existed prior to the RGWPM drilling campaign, while boreholes sited with the RGWPM are shown as blue circles with black dots with variable sizes, proportional to the yields. Three close-ups are shown in Fig. 3 (I, II and III) which will be referred to in the next section to illustrate specific mapping procedures.

The RGWPM map in Fig. 3 reveals that most wells drilled without the use of RGWPM (i.e. the small circles) are situated either in the low or slope GWP zones. The light blue larger circles with black dots show the positions of the eight wells sited using the RGWPM, which all fall within the medium GWP zone. The small light blue circles reflect wells within the medium GWP zone which were drilled prior to the development of RGWPMs and which are motorised with yields exceeding $5 \mathrm{~m}^{3} / \mathrm{h}$, all of which coincide with medium GWP zones, as shown in the RGWPM. The dark blue small circles reflect hand pumps with yields of $0.5-5 \mathrm{~m}^{3} / \mathrm{h}$ and can be seen to be mostly located in the low or slope area, while the black small circles filled with red reveal hand pumps which are located within the medium GWP area, but exploited at lower yields $\left(<5 \mathrm{~m}^{3} / \mathrm{h}\right)$. These hand pumps are potentially higher yielding indicating a potential for motorisation (therefore shown as 'underexploited' in the legend). The pink circles reflect hand pumps for which no yield data exist, most of which are also located within the low and slope GWP area.

The vast data set related to the wells shown in Fig. 3 will be further discussed in section 'Case study Bidibidi: quantifying impact and predictability of RGWPM', which focusses on quantifying the impact and predictability of RGWPM. Statistics of cumulative yields of the wells sited 'with' and 'without' RGWPM are then discussed, on the one hand, and, on the other hand, correlations are established between the classified yield data of all wells as related to the associated GWP zones to assess a posteriori the predictability of the RGWPM. In the following, the technical aspects of the RGWPM methodology which led to the RGWPM shown in Fig. 3 are discussed in detail and illustrated using the Bidibidi case.

\section{Constructing the map layers and RGWPM}

In this section, the technical aspects of constructing the RGWPM are discussed. First, the WA mapping procedures are presented, followed by the RC mapping procedures, and finally the overlay of WA and RC. The mapping of the different layers of the WA and the RC was done with the QGIS 3 software, while only the interpolation described in section low WA was done with SAGA GIS 2. Any mapping software allowing basic raster and vector operations are suitable for producing a RGWPM. In short, the main GIS manipulations are limited to a few subtractions of raster layers, combined with some manual corrections of morphological features using high-resolution satellite images. The satellite images used for mapping the starting points such as the Bing are brought in QGIS as XYZ tiles and the geological maps as WMS layers. 


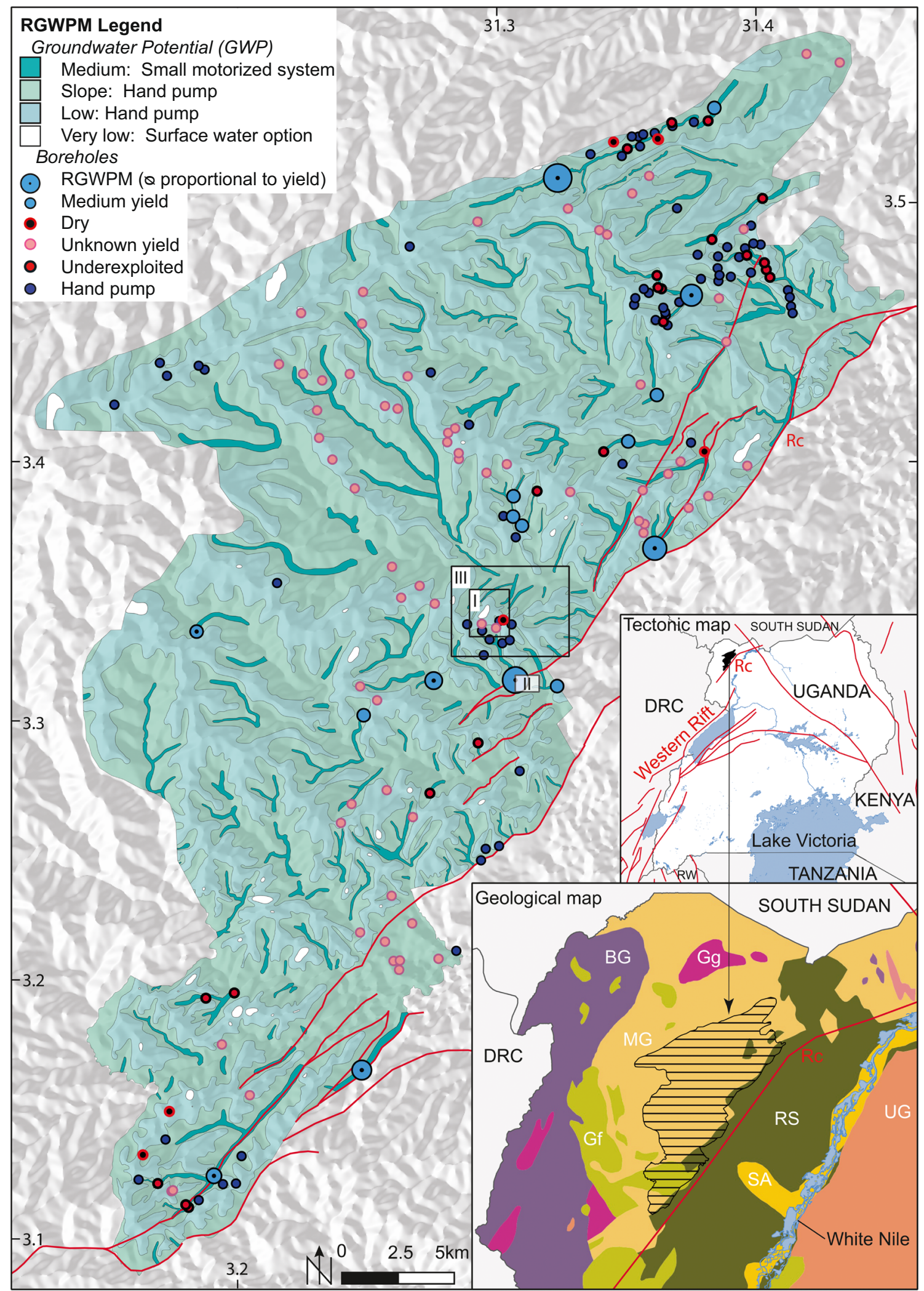


Fig. 3 RGWPM for Northern Uganda, in the district of Yumbe (Bidibidi refugee settlement). Four GWP zones are shown: medium (dark green), slope (green), low (light green) and very low (white). The red lines (Rc) are faults. Light blue circles with black dots: boreholes sited with RGWPM (diameter proportional to yield); light blue circles: boreholes located within medium RGWPM zones; red dots with black border: boreholes in medium GWP zone, either underexploited (yield $<5 \mathrm{~m}^{3} / \mathrm{h}$ ) or with unknown yield; black circles with red border: dry boreholes $\left(<0.5 \mathrm{~m}^{3} / \mathrm{h}\right)$; dark blue circles: hand pumps with yield information; pink circles: boreholes with unknown yield. Zones I, II and III are three closeups referred to in following figures. Bottom right: tectonic sketch $(1: 10 \mathrm{M})$ with regional faults along western branch of the East African rift (Thiéblemont et al. 2016); geology map (1:2 M) with major geological formations (DGSM 2004): BG banded gneisses, Gf granulite facies, Gg granitoid and highly granitized, MG Mirian gneisses, RS rift valley sediments, SA sediments, alluvium, black soils; UG undifferentiated gneisses; in north granulite facies, the fault is one of the regional faults of the rift. DRC Democratic Republic of Congo; RW Rwanda

Table 2 summarises all the mapping steps, from 1 to 11 which lead to the RGWPM. This table shows that the mapping methodology does not follow the units from one end to the other, but rather follows the logics of mapping units starting from the easiest to map unit towards the more difficult ones.

\section{Mapping the water availability}

The mapping procedure for the WA layer does not follow sequentially from low to high. Rather it starts with the construction of the low WA zone, within which the very low WA zone is then distinguished, as shown in Fig. 4. Then, in the second stage, the high WA is mapped. The remaining area reflects the slope unit, within which the medium WA is mapped. The remaining, unmapped areas then automatically fall into the slope WA.

\section{Low water availability}

The zone of low WA corresponds to the diffuse recharge zone, which is defined by the absence of any surface-water erosional features. It is obtained by mapping all starting points (i.e. channel initiation points), as indicated by black circles in Fig. 4. The mapping process of the starting points is a combination of computed drainage systems using the DEM (SRTM 1 arc-second) and then manually editing and correcting the points using high-resolution satellite images. The result of this process is a distribution of points $(\mathrm{x}, \mathrm{y}, \mathrm{z})$ defined by their coordinates and elevations extracted from the DEM. A simple natural neighbour interpolation was used to generate a surface containing all starting points, called 'A-surface', shown as a bold black line in the vertical cross-section in Fig. 4. The purely diffuse recharge area (low WA) is obtained by intersecting the constructed Asurface with the digital elevation model. The area which lies above the intersection of the two surfaces designates the area where no surface erosional features exist and thus qualifies as low WA zone, as shown in Fig. 4 as a map view (blue), as well as in the cross-section $\mathrm{AA}^{\prime}$.

\section{Very low water availability}

The very low WA zone is always contained within the low WA zone, i.e. within the area of the purely diffuse recharge zone and delimits areas where diffuse recharge is substantially restricted. There are two criteria that are used to map this zone: (1) outcropping bedrock or, (2) unsaturated regolithic weathering profile. Outcropping bedrock indicates that physical erosional processes dominate the weathering processes, suggesting lateral sediment transport rather than vertical infiltration. Using satellite imagery to identify exposed bedrock is one way of identifying the very low WA within the low WA. Additional remote sensing products, such as NDVI or LandSat can be used in combination, particularly in areas where intertwined vegetation and slight soil cover blur outcrops.

In most regoliths encountered across the Sub-Saharan region, groundwater accumulation is very often encountered at the interface between the weathered profile and the unaltered bedrock (Chilton and Foster 1995). Groundwater flow along this interface can substantially contribute to groundwater resources in the low WA area but also contributes to recharge of groundwater in deeper fractured zones. Hence, in areas where the base of the weathering profile is topographically higher than the surface erosional features of the channel initiation points, i.e. above the A-surface, it is argued that the formation of a continuous groundwater body is greatly reduced. This argument has led to simply deducting from the digital elevation model $20 \mathrm{~m}$, assumed this as an average depth of the regolith weathering profile where such groundwater bodies can occur (Taylor and Howard 2000; Chilton and Foster 1995; stippled line in cross section $\mathrm{AA}^{\prime}$ of Fig. 4). Intersecting this fresh bedrock hypothetical topography with the A-surface results in the very low WA zone, being the area above the A-surface (white area Fig. 4).

\section{High water availability}

The high WA corresponds to discharge areas of groundwater where water is always available. Groundwater discharge areas are either connected to surface-water bodies, such as to lakes and streams, or they form springs or wetlands. Hence, the mapping process for this zone consists of mapping perennial surface-water features. The mapping process should be done using dry seasonal satellite images - as an example, Fig. 5 shows one of the few areas where a perennial stream could be mapped in the Bidibidi (dark blue area). The dry season in 2018 in Uganda extended from January to March, as shown in the bottom left graph illustrating the daily precipitation as obtained from Google Earth Engine (CHIRPS). A Google 
Table 2 The schematic step-bystep process, from 1 to 11 , leading to RGWPM, revealing for each overlay unit which data sets were used. Figure references are given which are further discussed in the text. $D E M$ digital elevation model; $W A$ water availability; $\mathrm{RC}$ reservoir capacity

\begin{tabular}{|c|c|c|c|c|c|c|}
\hline \multirow{2}{*}{$\begin{array}{l}\text { Map } \\
\text { variable }\end{array}$} & \multirow{2}{*}{$\begin{array}{l}\text { Figure references } \\
4-7\end{array}$} & \multicolumn{5}{|l|}{ Map units } \\
\hline & & Very low & Low & Slope & Medium & High \\
\hline \multirow[t]{7}{*}{ WA } & 4 & - & Step 1 & - & - & - \\
\hline & 4 & Step 2 & - & - & - & - \\
\hline & 5 & - & - & - & - & Step 3 \\
\hline & 6 & - & - & - & Step 4 & - \\
\hline & 6 & - & - & Step 5 & - & - \\
\hline & Required data sets & $\begin{array}{l}\text { DEM, LandSat, } \\
\text { Satellite image }\end{array}$ & $\begin{array}{l}\text { DEM, Sat. } \\
\text { image }\end{array}$ & - & $\begin{array}{l}\text { DEM, Sat. } \\
\text { image }\end{array}$ & $\begin{array}{l}\text { LandSat, Sat. } \\
\text { image }\end{array}$ \\
\hline & \multicolumn{6}{|c|}{ Step 6: Water availability overlay WA $(\mathrm{x}, \mathrm{y})$ : combination of steps $1-5$} \\
\hline \multirow[t]{5}{*}{$\mathrm{RC}$} & - & \multicolumn{2}{|l|}{ Step 7} & - & - & - \\
\hline & 7 & - & - & - & Step 8 & - \\
\hline & - & - & - & - & - & Step 9 \\
\hline & Required data sets & \multicolumn{2}{|c|}{$\begin{array}{l}\text { Geological map, LandSat, } \\
\text { Satellite image }\end{array}$} & - & $\begin{array}{l}\text { Sat. image, } \\
\text { Geol. map }\end{array}$ & $\begin{array}{l}\text { Sat. image, } \\
\text { Geol. map }\end{array}$ \\
\hline & \multicolumn{6}{|c|}{ Step 10: Reservoir capacity overlay RC $(\mathrm{x}, \mathrm{y})$ : combination of steps $7-9$} \\
\hline \multicolumn{7}{|c|}{ Step 11: RGWPM: Overlay of WA (x,y) and RC (x,y) } \\
\hline
\end{tabular}

Earth image from 01/02/2018 (Fig. 5a) taken in the middle of the dry season shows where the stream becomes perennial, i.e. starts to exfiltrate. In order to cross-validate the positioning of the high WA with the Google Earth image, a composite NDVI

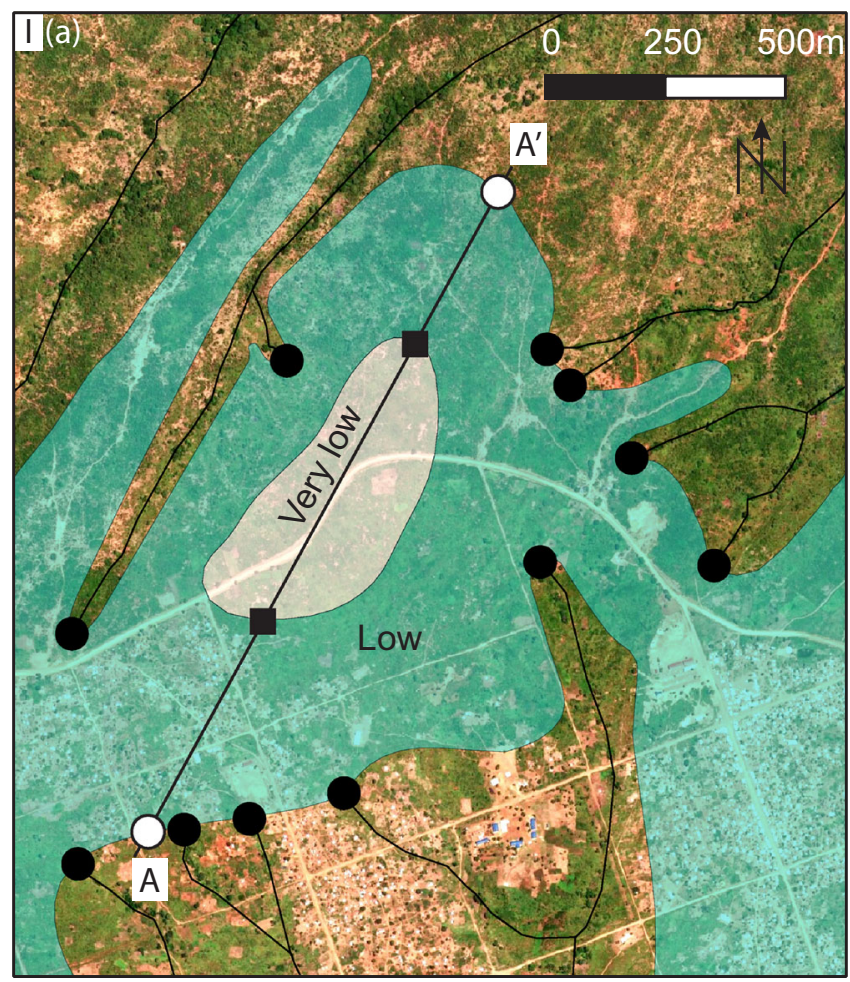

Fig. 4 a Close up I of Fig. 3 with starting points or channel initiation points (black dots) and drainage network (thin back lines). The light green and white areas present respectively low and the very low water availability (WA). b Cross-section AA' showing the constructed 'A-surface' (bold black line) intersecting the topography (brown line). The image, also obtained with Google Earth Engine (LC08) between January and March 2018 (Fig. 5b), shows healthy vegetation (high NDVI values) along this stream, indicating the presence of near groundwater or perennial surface water.

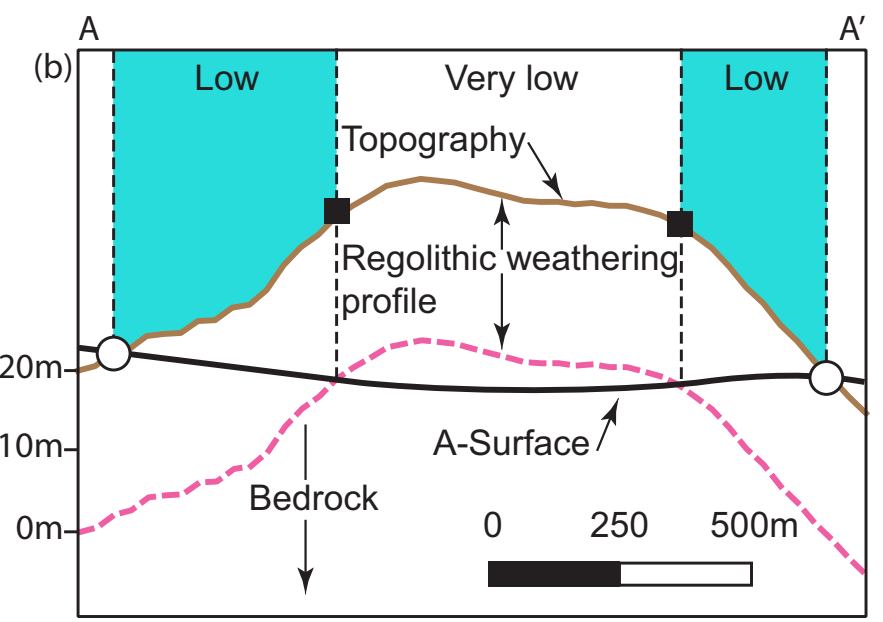

hypothetical bedrock is shown as dashed pink line, $20 \mathrm{~m}$ below topography: intersection with A-surface delimits the very low GWP area. White circles and black squares illustrate the intersection of the A-surface with topography profile $\mathrm{AA}^{\prime}$ delimiting the low and very-low WA, respectively 


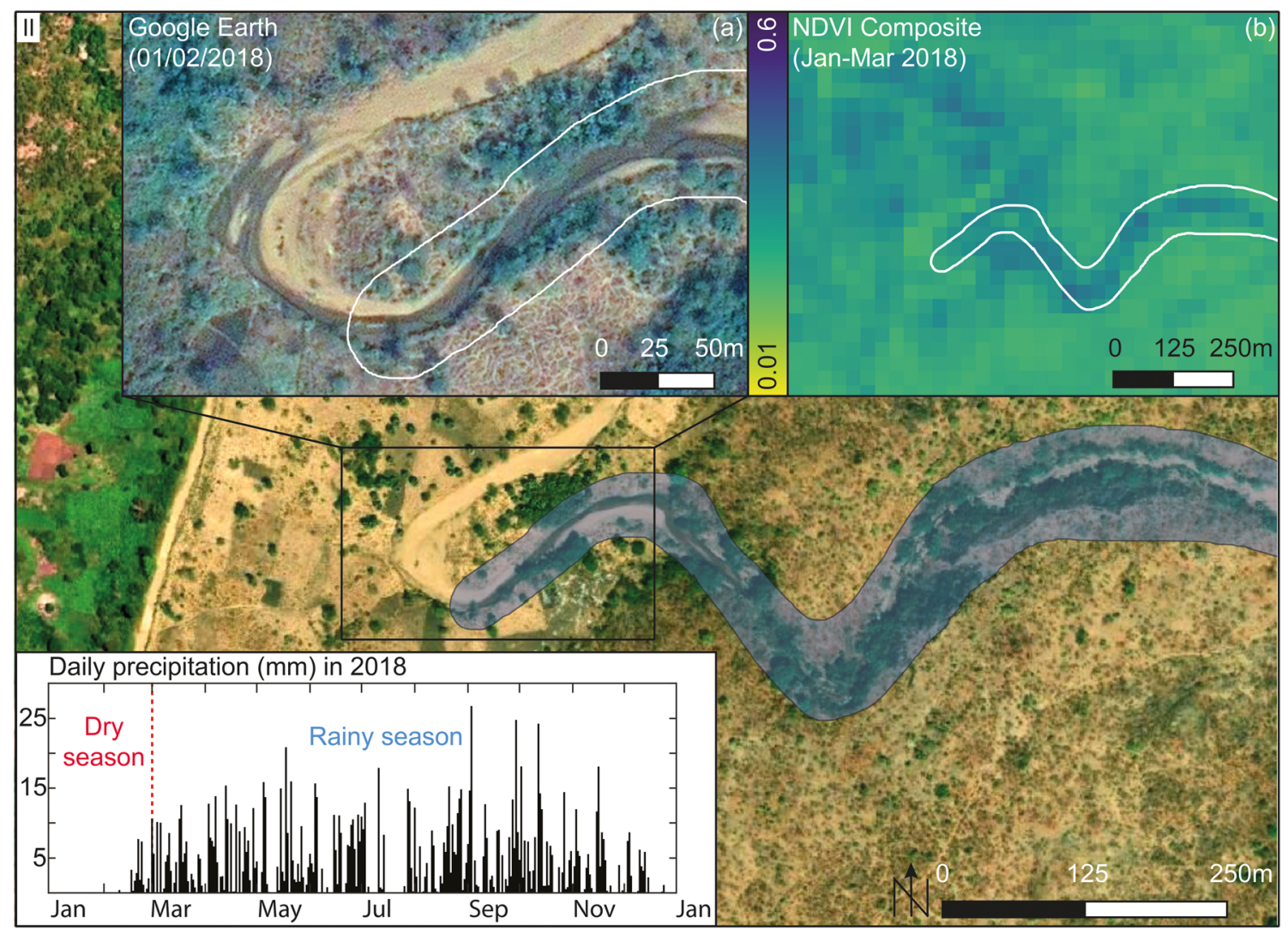

Fig. 5 Close up II of Fig. 3 with the High WA zone (blue). This zone is defined by a perennial stream mapped using the Google Earth image of $01 / 02 / 2018$. a The beginning of the perennial stream is where the colour of the streambed becomes darker; b cross-validation with NDVI

\section{Medium water availability}

According to the conceptual framework (Fig. 1), the medium WA is situated in the slope unit, along the drainage network, where concentrated recharge can take place. A method is proposed to distinguish the low WA from the medium WA, since these are adjacent in the conceptual model, meeting at the channel initiation points. If the medium WA goes all the way to the starting points, the starting point itself would belong to both the low and the medium WA zone at the same time, which is misleading. As concentrated recharge cannot really take place at the channel initiation point, where runoff only just begins, it is conceptually reasonable to start the medium WA zone at the first order junction, as illustrated in Fig. 6 by large light blue dots. A buffer of $100 \mathrm{~m}$ is drawn around the drainage network to delimit the medium WA, coherent with the target resolution of the maps for geophysical campaigns.

\section{Slope water availability}

As can be seen in Fig. 6, the only zone which remains unmapped at this stage is the slope WA area, as discussed and shown in Figs. 1 and 2. Hence, this zone is in an composite (January-March 2018) where high (blueish) values indicate healthy vegetation due to the proximity of groundwater or perennial surface water. The 2018 daily precipitation in millimetres (bottom left) illustrates the dry season from January to March 2018

intermediate position between the low and the medium WA, characterised by purely diffuse recharge like in the low WA, but also with axial groundwater flow, as in the medium WA. This intermediate position has led to this separate WA class. Since it is the only unmapped area at the end of the WA mapping procedure, slope WA is simply assigned to the entire unmapped area.

\section{Mapping the reservoir capacity}

In this section, the mapping procedure leading to the $\mathrm{RC}$ layer is presented. The $\mathrm{RC}$ attempts to assign one of the four hydraulic conductivity classes defined in Table 1 to all lithologies and tectonic features in an area of interest. The errors committed in assigning hydraulic conductivities are somewhat alleviated by the fact that the estimations are made on orders of magnitude rather than on absolute hydraulic conductivities. In the RGWPM matrix shown in Fig. 2, the sign $\approx$ used for the hydraulic conductivity classes suggests that the absolute range end-member values require some hydrogeological expert judgement, and, whenever possible, on data from existing boreholes. 


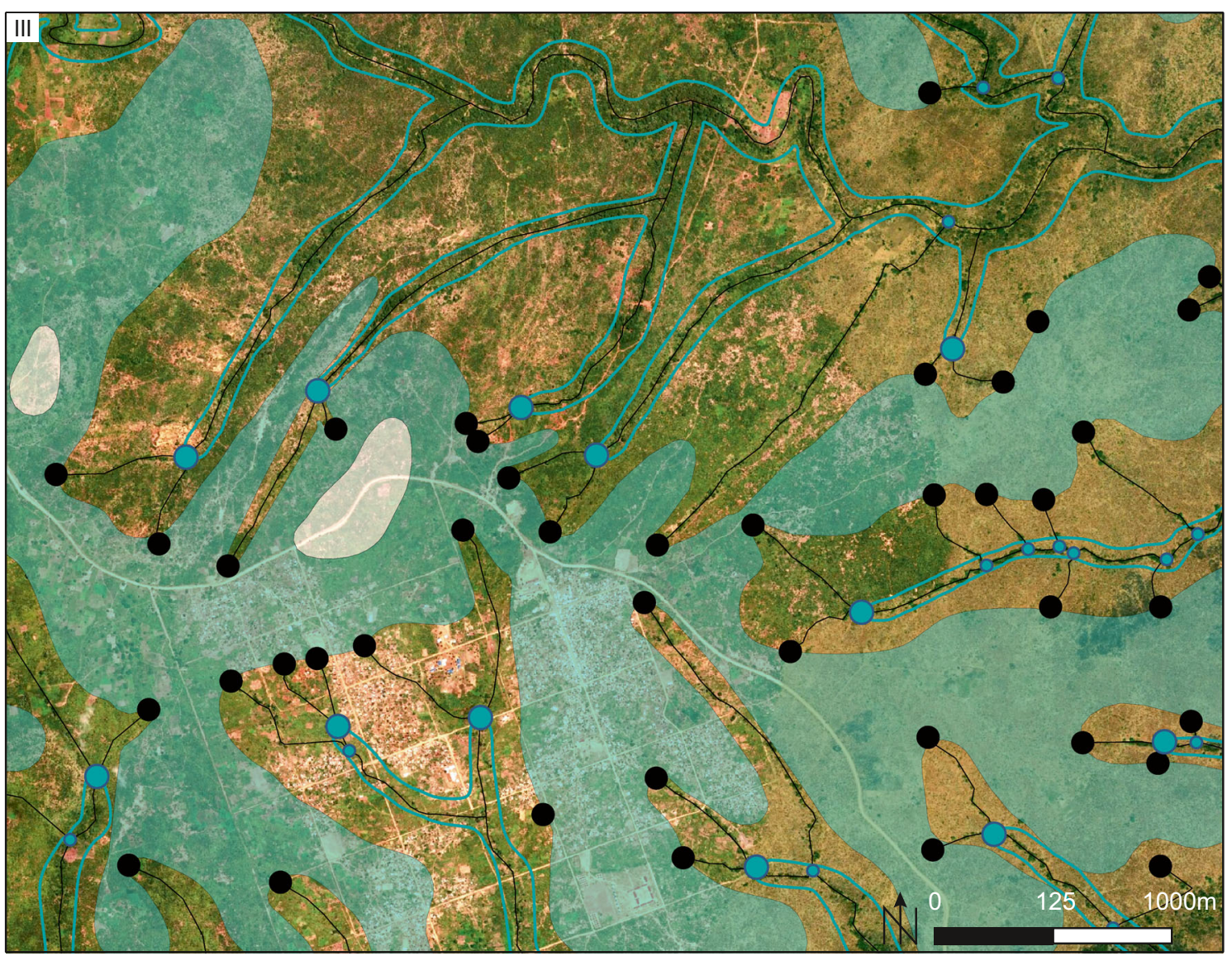

Fig. 6 Close up III of Fig. 3 showing the mapping procedure of the medium WA. The black dots mark the starting points used to construct the low WA zones. Light blue dots indicate first order junctions of drainage channels with the basin network. Large blue dots indicate

\section{Low reservoir capacity}

In vast areas across the African Precambrian shield covered with regolith it has been demonstrated that the saprolite has a typical hydraulic conductivity around $10^{-6} \mathrm{~m} / \mathrm{s}$ (e.g. Dewandel et al. 2006). Hydraulic tests conducted in saprolite in Uganda reveal a median hydraulic conductivity of $4.6 \times$ $10^{-6} \mathrm{~m} / \mathrm{s}$ (Taylor and Howard 2000) and for less specific weathered granite a range between $3.3 \times 10^{-6}$ and $5.2 \times 10^{-5}$ $\mathrm{m} / \mathrm{s}$ has been documented (Domenico and Schwartz 1990). Within the RGWPM this hydraulic conductivity range would ascribe the regolith to the medium $\mathrm{RC}$ class according to the hydraulic conductivity ranges of Table $1\left(10^{-6}-10^{-5} \mathrm{~m} / \mathrm{s}\right)$. However, the groundwater bodies contained within saprolite will hardly ever yield more than a few $\mathrm{m}^{3} / \mathrm{h}$, colloquially known as 'hand pump' country. Therefore, the RC would probably be overestimated by the use of textbook hydraulic conductivities and therefore, if hydraulic conductivities are expected to be close to the lower end of the range, it is advisable to assign it to the lower RC class. However, hydraulic conductivities should not be underestimated by setting it below a low RC either, as the majority of hand pumps across upstream second order junctions defining the beginning of the medium WA. Buffer of hundred meters around the channels is then added to define the medium WA (green lines)

Africa prove the opposite, since they are drilled in nonfractured regolith. In both cases, this balancing act between medium and low RC is largely alleviated by first mapping the WA overlay and excluding the low and very low WA areas from the RC mapping domain.

\section{Medium reservoir capacity}

In a regolithic environment, the mappable fracture zones are assigned to the next higher RC class as compared to the host rock. In regolithic areas such as in Bidibidi, these faults and fracture zones are therefore assigned to the medium RC class, since the surrounded host rock was assigned to the low RC class. It must be kept in mind that fractured igneous and metamorphic rocks according to Freeze and Cherry (1979) are unlikely to have a higher hydraulic conductivity than approximately $10^{-4} \mathrm{~m} / \mathrm{s}$, which means that high $\mathrm{RC}$ in fracture zones can in some rare cases be expected. Assigning a fracture zone to the high RC class, requires, however, some sound hydrogeological rationale. In the majority of cases, where fault zones appear as geomorphological features it seems 
reasonable, therefore, to assign them to the medium $\mathrm{RC}$ class.

In the Bidibidi case study, fault and fracture zones were mapped by identifying rectilinear lineaments using satellite images. These features range between a few hundred meters for fractures to several kilometres for the fault zones, as shown in Fig. 3 (red lines). The vegetation is an additional useful indicator for mapping these features, because evergreen plants such as large trees preferentially grow along them. This type of vegetation usually draws a line of darker shade of green than the surrounding smaller plants such as grass. In Fig. 7, the red lines show the fracture zones mapped within the medium WA (light blue). Lineaments are also encountered within low or slope WA zones, but do not have to be mapped, since the GWP will be dictated by the lower WA during the overlay process.

\section{High reservoir capacity}

The earth material which can most safely be assigned to the high RC class with hydraulic conductivity easily exceeding
$10^{-5} \mathrm{~m} / \mathrm{s}$ are alluvial deposits such as sand and gravels, for instance along Wadis. This type of material was not encountered anywhere in Bidibidi.

\section{RGWPM: overlay of the water availability and the reservoir capacity}

The WA and RC being mapped, the last step of the RGWPM methodology consists in overlaying the two variables and determining the GWP according to the matrix (Fig. 2) with the lower of the two classes defining the GWP. The variable WA has been mapped regardless of RC but not vice-versa. In this case study, the largest area of the RGWPM is covered by low and slope WA, which will define the GWP. Many fracture zones (medium RC) fall within the large low and slope WA zone, but did therefore not need to be mapped at all, since a medium RC will not change the resulting GWP, set by the low WA. For that reason, the fracture and fault zones were only mapped within the medium WA. In that sense, the term overlay is conceptual rather than practical, since the overlay process evolves while the mapping proceeds, which resulted in the RGWPM shown in Fig. 3.

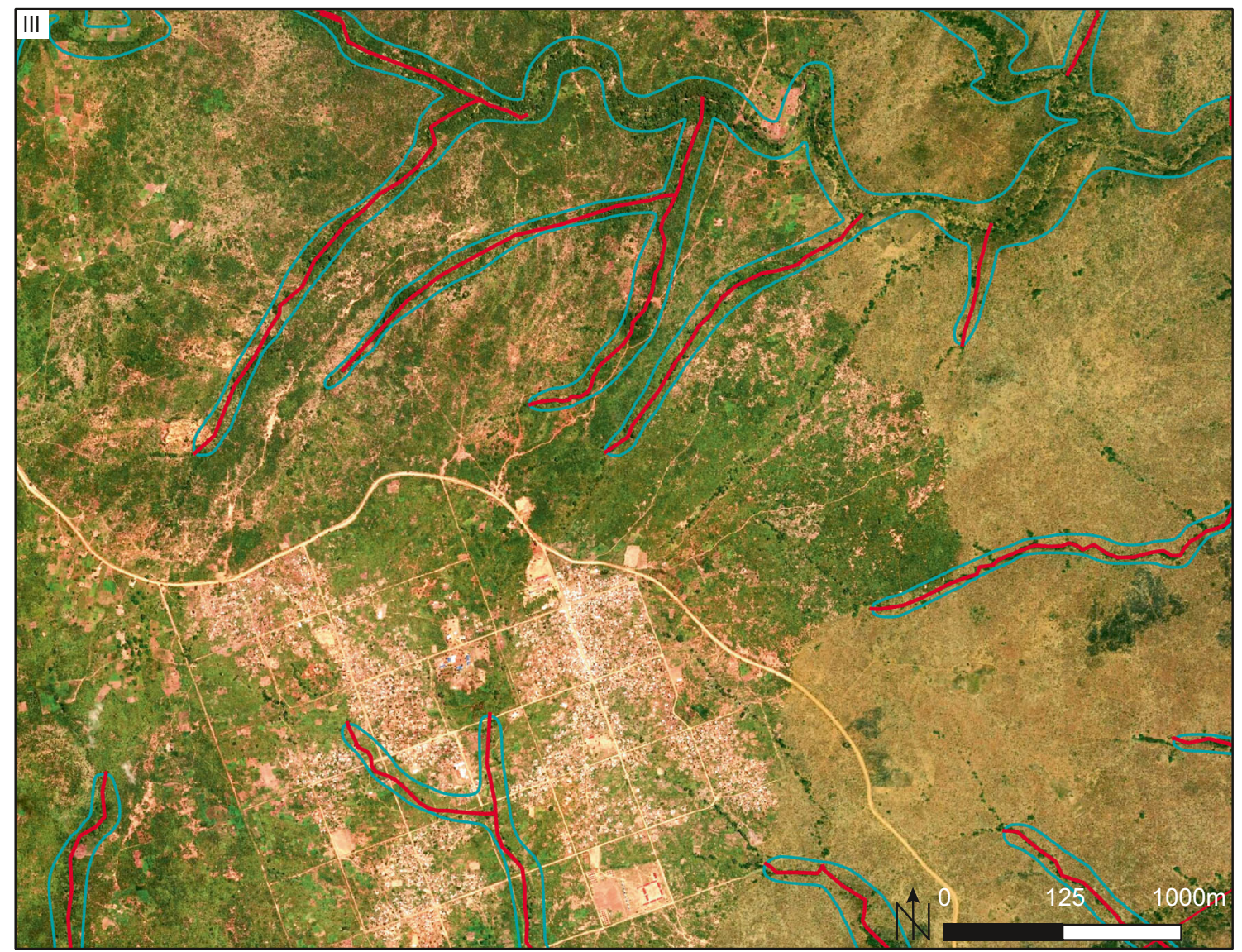

Fig. 7 Close up III of Fig. 3 showing the lineaments related to fractures (red lines) associated with medium RC mapped within the medium WA areas (green lines) 


\section{Case study Bidibidi: quantifying impact and predictability of RGWPM}

This section explores the impact and predictability of the RGWPM used in the Bidibidi refugee settlements to site eight boreholes (Fig. 3). Two different analyses are presented - the first compares the yield as well as drilled depth of the boreholes sited 'with' the RGWPM with the boreholes drilled without RGWPM (hereafter called 'existing boreholes'); the second analysis uses the data from the existing boreholes to compare the actual well yields with the RGWPM predicted yield classes. These data are independent and were not used to establish the RGWPM. This comparison allows crossvalidation of the RGWPM approach by assessing the match between the RGWPM predicted yield classes and the reality.

Throughout this section, it has to be kept in mind that the quality of the borehole data retrieved from numerous humanitarian agencies is highly heterogeneous. With yield data forming the most important data set for the following analysis, interpretation seeks to account for the different 'data quality' and origins. In the best case, yield data are based on pump test interpretation and in the worst case they are simply a driller's estimate during borehole development, or simply the highest pump test yield. This was typically found to be the case for numerous pump tests carried out for hand pumps, which simply document the maximum test yield of $0.8 \mathrm{~m}^{3} / \mathrm{h}$ as borehole yield. This kind of yield data may be misleading, because it does not necessarily reflect the actual borehole yield, but simply confirms that the highest test yield can be sustained.

\section{Comparative statistics of borehole sites with and without RGWPM}

The data for the comparative analysis of the eight boreholes sited with the RGWPM in Bidibidi and the 176 existing wells sited without RGWPM are shown in Fig. 8a (table) and Fig. $8 \mathrm{~b}$ (RGWPM map). For a larger version of the RGWPM map please refer to Fig. 3. Figure 8 is subdivided into three 'data families' shown horizontally: those with yield data, those with drilling depth data and those with both yield and drilling depth data. Data from boreholes drilled without RGWPM and those drilled with RGWPM are presented for each of these groups.

The first line in the table of Fig. 8a shows the total number of boreholes used for the analysis. Below, there are three separate boxes highlighted in different white-grey shadings. The white data box shows the sub-data set which includes all boreholes for which yield data are available. A total of 92 existing boreholes were used, meaning that no yield data are available for 84 boreholes, which are shown as pink circles in the RGWPM in Fig. 8b, all of which are hand pumps. The second line in the table shows the cumulative yield, revealing $272 \mathrm{~m}^{3} /$ $\mathrm{h}$ for the existing wells versus $283 \mathrm{~m}^{3} / \mathrm{h}$ for the RGWPM sited boreholes. Hence, $8 \%$ of the boreholes ( 8 RGWPM boreholes) extract $51 \%$ of the total yield, while $92 \%$ of the boreholes (92 existing boreholes) extract $49 \%$. This leads to an average borehole yield of $3 \mathrm{~m}^{3} / \mathrm{h}$ for the existing boreholes versus $35 \mathrm{~m}^{3} / \mathrm{h}$ for the RGWPM sited boreholes.

On the other hand, considering the cumulative yield of the existing boreholes of $272 \mathrm{~m}^{3} / \mathrm{h}, 135 \mathrm{~m}^{3} / \mathrm{h}$, i.e. $50 \%$, are extracted from 8 motorised systems (all located within the medium GWP zone, shown as blue circles in Fig. 3), most probably sited based on expert advice. Adding the yields of the 16 motorised boreholes, representing $10 \%$ of all boreholes, the existing 8 boreholes $\left(135 \mathrm{~m}^{3} / \mathrm{h}\right)$ and the 8 RGWPM sited boreholes $\left(283 \mathrm{~m}^{3} / \mathrm{h}\right)$, yields $418 \mathrm{~m}^{3} / \mathrm{h}$, corresponding to $75 \%$ of the total yield.

This very simplistic statistical comparison definitely suggests that RGWPM siting has had a major impact on the borehole yields on the one hand and, on the other hand, that the medium GWP zone is far more high-yielding than the rest, increasing the average borehole yield by approximately one order of magnitude.

This result may be distorted by the fact that 84 existing boreholes without yield data have not been included in this assessment. If an average yield of $2 \mathrm{~m}^{3} / \mathrm{h}$ is assumed for all these boreholes, corresponding to the average yield of boreholes with yield data located within the low GWP zone, then the cumulative yield of the existing 176 wells would be 440 $\mathrm{m}^{3} / \mathrm{h}$, versus $283 \mathrm{~m}^{3} / \mathrm{h}$ of the 8 RGWPM sited wells. In that case, the RGWPM boreholes would still be extracting $39 \%$ of the cumulative yield with only $4 \%$ of the boreholes.

Belonging to the second data family are those boreholes with data on depth or drilled length. These are presented in the section shown as a light grey box in Fig. 8a. For this analysis, 76 existing boreholes were identified containing this information. The cumulative borehole depth of the existing wells is $6,115 \mathrm{~m}$, reflecting $86 \%$ of the total drilled length in Bidibidi, while the eight RGWPM sited boreholes have a cumulative depth of $964 \mathrm{~m}$, corresponding to $14 \%$ of the total drilled length. The average borehole depth of the existing wells is $80 \mathrm{~m} / \mathrm{BH}$, while for the RGWPM sited boreholes it is $121 \mathrm{~m} / \mathrm{BH}$. Hence, borehole depth may also be relevant and is of course completely independent of the RGWPM approach, which does not suggest any drilling depth.

Belonging to the third data family are those boreholes with both yield and drilling depth, and are shown in the dark grey box in Fig. 8a. The 69 existing boreholes with both data sets had a cumulative yield of $242 \mathrm{~m}^{3} / \mathrm{h}$, versus a cumulative yield of $283 \mathrm{~m}^{3} / \mathrm{h}$ for the RGWPM sited boreholes, leading to average yields of 4 and $35 \mathrm{~m}^{3} / \mathrm{h}$ and average borehole depths of 80 and $121 \mathrm{~m}$, respectively. From these data, the specific borehole depth-yield was calculated, reflecting how many meters were drilled to for each $\mathrm{m}^{3}$ of water, which is a very visual way of quantifying productivity of wells. For the existing boreholes, an average of $27 \mathrm{~m}_{\mathrm{BH}} /\left[\mathrm{m}^{3} / \mathrm{h}\right]$ is obtained, versus only $3 \mathrm{~m}_{\mathrm{BH}} /\left[\mathrm{m}^{3} / \mathrm{h}\right]$ for the RGWPM sited boreholes, again 
(a)

\begin{tabular}{|c|c|c|c|c|c|}
\hline \multicolumn{3}{|l|}{ (a) } & $\begin{array}{l}\text { BH sited without } \\
\text { RGWPM (existing) }\end{array}$ & $\begin{array}{c}\text { BH sited with } \\
\text { RGWPM }\end{array}$ & All BH \\
\hline \multicolumn{3}{|c|}{$\begin{array}{c}\text { Number of boreholes (BH) in RGWPM } \\
\text { Bidibidi (Figure3), with and without } \\
\text { yield \& depth data }\end{array}$} & 176 & 8 & 184 \\
\hline \multirow{4}{*}{ 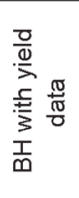 } & Number of boreholes & No. BH & 92 & 8 & 100 \\
\hline & Cumulated & $\mathrm{m}^{3} / \mathrm{h}$ & 272 & 283 & 555 \\
\hline & Relative & $\%$ & 49 & 51 & 100 \\
\hline & Average & $\mathrm{m}^{3} / \mathrm{h} / \mathrm{BH}$ & 3 & 35 & 6 \\
\hline \multirow{4}{*}{$\begin{array}{l}\frac{5}{\overline{0}} \\
\frac{0}{0} \\
\frac{0}{0} \\
\frac{5}{\frac{\pi}{\pi}} \\
\frac{1}{3} \\
\frac{1}{0} \\
\frac{1}{\infty}\end{array}$} & Number of boreholes & No. BH & 76 & 8 & 84 \\
\hline & Cumulated & $\mathrm{m}$ & 6115 & 964 & 7079 \\
\hline & Relative & $\%$ & 86 & 14 & 100 \\
\hline & Average & $\mathrm{m} / \mathrm{BH}$ & 80 & 121 & 84 \\
\hline \multirow{6}{*}{ 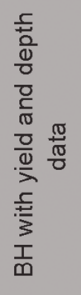 } & Number of boreholes & No. BH & 69 & 8 & 77 \\
\hline & Cumulated yield & $\mathrm{m}^{3} / \mathrm{h}$ & 242 & 283 & 525 \\
\hline & Average yield & $\mathrm{m}^{3} / \mathrm{h} / \mathrm{BH}$ & 4 & 35 & 7 \\
\hline & Cumulated depth & $m$ & 5516 & 964 & 6480 \\
\hline & Average depth & $\mathrm{m} / \mathrm{BH}$ & 80 & 121 & 84 \\
\hline & Specific BH depth-yield & $\mathrm{m}_{\mathrm{BH}} /\left[\mathrm{m}^{3} / \mathrm{h}\right]$ & 27 & 3 & 15 \\
\hline
\end{tabular}

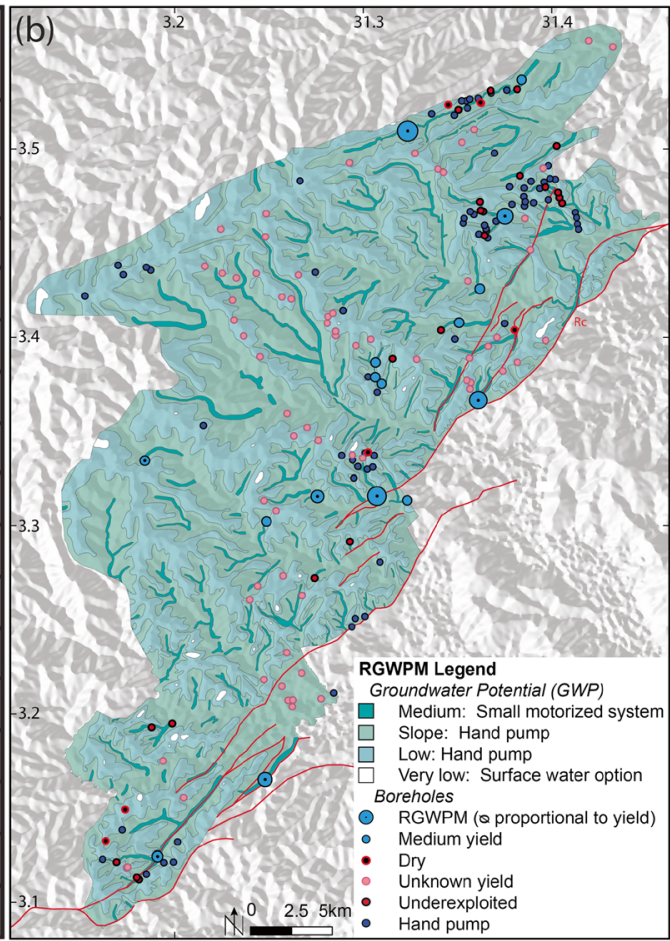

Fig. 8 a Table showing the key data used for the statistical comparison of existing boreholes sited without RGWPM (first column) and for boreholes sited with RGWPM (second column) and all boreholes (last column), with subdivision of data into boreholes containing yield data

and boreholes with depth data. Boreholes with both yield and depth data are shown in the dark grey table section. b Miniature RGWPM, corresponding to Fig. 3, for rough overview

pointing towards a far higher productivity per meter drilled of the RGWPM sited boreholes. This is an operationally interesting result, pointing both towards positive impact of RGWPM for siting and also towards positive impact of increased borehole depth $(80 \mathrm{~m}$ for existing $\mathrm{BH}$ and $121 \mathrm{~m}$ for RGWPM sited BH).

Although the data quality is highly heterogeneous and the statistical comparison was made with only eight RGWPM sited boreholes, the results suggest that using a physically based, although simplistic approach such as the RGWPM, has had a significant positive impact on the yield in the Bidibidi case study.

\section{Assessing actual borehole yields with RGWPM predicted 'yield classes'}

In this section, the data set of the existing boreholes, sited without the RGWPM containing yield data, is used to assess how the RGWPM map, shown in Fig. 3, performs in predicting the yield range. For that purpose, it is important to leave aside the boreholes sited with RGWPM, in order to have an independent data set. The process involves extracting the 'GWP' zone associated to each existing borehole from the RGWPM and classifying the yields of all wells into the RGWPM yield classes. This leads to a matrix, shown in the table of Fig. 9a, in which the GWP zones of the RGWPM are shown in columns and the classified yields in lines, indicating the number of boreholes falling into each yield class. The matrix shows that 20 of the existing boreholes fall into the low GWP zone, 48 into the slope GWP zone and 24 into the medium GWP zone. In Fig. 9b, the individual yields of the eight RGWPM sited boreholes, all located within the medium GWP zone, are shown in a separate graph, revealing that six boreholes fall into the medium yield class $\left(5-50 \mathrm{~m}^{3} / \mathrm{h}\right)$ and three boreholes fall into the high yield class $\left(>50 \mathrm{~m}^{3} / \mathrm{h}\right)$. The average yield of $35 \mathrm{~m}^{3} / \mathrm{h}$ is indicated with a red stippled line. In Fig. 9c, the data from the existing boreholes shown in the matrix in Fig. 9a are represented as percentages of boreholes assigned to different yield classes within each GWP zone.

\section{Low and slope GWP zone}

In the RGWPM approach, these two GWP zones are associated with the low yield class, i.e. to yield ranging from 0.5 to 5 $\mathrm{m}^{3} / \mathrm{h}$. The difference between the two GWP zones, as discussed earlier, is mainly the fact that the slope GWP zone is not only related to diffuse recharge but is better positioned with respect to axial groundwater flow from the upland unit, suggesting more stable groundwater conditions with smaller seasonal variations, but not higher yields.

Figure $9 \mathrm{c}$ reveals that $15 \%$ of the 20 boreholes drilled in the low GWP zone have very low yields, $<0.5 \mathrm{~m}^{3} / \mathrm{h}$, while $75 \%$ of 
(a)

\begin{tabular}{|c|c|c|c|c|c|c|}
\hline \multirow{3}{*}{ 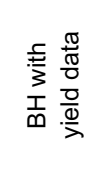 } & $\begin{array}{c}\text { Number of } \\
\text { boreholes }\end{array}$ & No. BH & 92 & 20 & 48 & 24 \\
\hline & Cumulated & $\mathrm{m}^{3} / \mathrm{h}$ & 272 & 40 & 75 & 157 \\
\hline & Average & $\mathrm{m}^{3} / \mathrm{h} / \mathrm{BH}$ & 3 & 2 & 2 & 7 \\
\hline \multirow{3}{*}{ 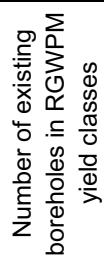 } & $\begin{array}{c}\text { "Very low" : }<0.5 \\
\mathrm{~m}^{3} / \mathrm{h}\end{array}$ & $\mathrm{BH} /$ class & 5 & 3 & 2 & 0 \\
\hline & $\begin{array}{c}\text { "Low" : } 0.5 \text { - } 5 \\
\mathrm{~m}^{3} / \mathrm{h}\end{array}$ & $\mathrm{BH} /$ class & 74 & 15 & 43 & 16 \\
\hline & $\begin{array}{l}\text { "Medium" : } \\
5-50 \mathrm{~m}^{3} / \mathrm{h}\end{array}$ & $\mathrm{BH} /$ class & 13 & 2 & 3 & 8 \\
\hline
\end{tabular}

(b)

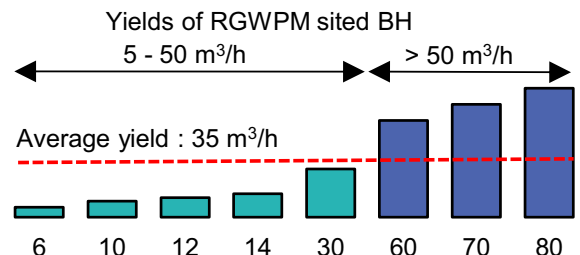

$\mathrm{m}^{3} / \mathrm{h}$

(c)

GWP

zones for the eight boreholes sited with RGWPM, with six within the medium yield class $\left(5-50 \mathrm{~m}^{3} / \mathrm{h}\right)$ and three boreholes within the high yield class $\left(>50 \mathrm{~m}^{3} / \mathrm{h}\right)$, with indicated average yield of $35 \mathrm{~m}^{3} / \mathrm{h}$; c graphs showing the relative distribution of existing boreholes within each GWP zone with the colours referred to (a) the boreholes have yields falling into the low yield class, which is the class associated with the GWP zone. Only $10 \%$ of the boreholes ( $2 \mathrm{BHs}$ ) have medium yields, exceeding 5 $\mathrm{m}^{3} / \mathrm{h}$. This suggests a rather good predictability of the RGWPM for the low zone, with only $25 \%$ of outliers on each side.

Similar to the low GWP zone distribution, the slope GWP zone borehole yield distribution shown in Fig. 9c reveals that $90 \%$ of the boreholes (43 BHs) located within the slope unit, have low yields ranging between 0.5 and $5 \mathrm{~m}^{3} / \mathrm{h}$, with only $4 \%$ (2 BHs) having lower yields and $6 \%$ yields exceeding 5 $\mathrm{m}^{3} / \mathrm{h}$ (3 BHs). Here again, the predictability of the RGWPM is very good.

Overall, for the low and slope GWP zones together, both zones associated with the yield range of $0.5-5 \mathrm{~m}^{3} / \mathrm{h}, 85 \%$ of the existing borehole yields actually do so, while $7.5 \%$ have higher and $7.5 \%$ lower yields. Hence, the yields of these 68 boreholes could have been predicted with $85 \%$ certainty if the RGWPM had already existed at the time of drilling. A highly relevant aspect of the high predictability of the RGWPM for low yield classes is that 'low yield class' areas can rapidly be defined, thus rapidly excluding uninteresting zones for water development.

\section{The medium GWP zone}

The medium GWP zone in the RGWPM approach is associated to yields in the range of $5-50 \mathrm{~m}^{3} / \mathrm{h}$, for small-to-medium motorised systems. Figure $9 \mathrm{c}$ reveals that only $33 \%$ of the 24 boreholes located in this zone having documented yields exceeding $5 \mathrm{~m}^{3} / \mathrm{h}$, all of which are motorised. In all, $67 \%$ of the medium zone boreholes (16 BHs, all hand pumps) have yields in the low yield class range, of $0.5-5 \mathrm{~m}^{3} / \mathrm{h}$. One reason for this mismatch could possibly be 'poor' predictability of the
RGWPM for the medium GWP zone; however, having performed $100 \%$ for the boreholes sited with the RGWPM within the medium zone points towards another explanation. The high percentage of boreholes in the medium GWP zone having a low yield class may therefore simply be related to the fact that they were drilled to be hand pumps (all of them are), leading to low documented yields. All these boreholes are shown in Fig. 3 as black circles filled with red and are described as 'underexploited', since they have a medium RGWPM predicted yield class, suggesting they could be motorised $\left(>5 \mathrm{~m}^{3} / \mathrm{h}\right)$. This observation was an unexpected result of this cross-validation process, suggesting an alternative use of RGWPM to identify existing wells which could potentially be upgraded to motorised pumping or even solar pumping systems. This is highly relevant, since conversion to solar pumping is an operational priority for UNHCR and its partners. Using the RGWPM to prioritise wells to be retrofitted, concentrating on hand pumps located within the medium GWP zone, may be a significant added value of these maps.

Although the RGWPM approach has only been crossvalidated in the Bidibidi case study, the results suggest that significant improvements can be made by using RGWPM and targeted geophysics. Particularly in humanitarian contexts, where the alternative is mostly 'no strategy' other than drilling rapidly and close to people. The RGWPM is believed to be a highly useful approach, which certainly has a potential to be replicated in other areas in the Sub-Saharan belt with similar geological conditions.

The Bidibidi case-study and RGWPM cross-validation process has revealed that not only is the predictability of the expected 'yield classes' quite good, allowing strategic planning of small-scale geophysical investigations, but this also 
highlighted that the low and slope GWP areas should be avoided for prospection, if solarised/motorised systems are targeted. A surprising but operationally significant result of this case study was also to identify numerous hand pumps situated within the medium GWP zone, suggesting that such boreholes should be prioritised if retrofitting of hand pumps to solar-powered motorized systems is envisaged.

Looking at the results presented in the preceding section, revealing significant differences in yields between boreholes sited with and without RGWPM, one is tempted to ponder on what the borehole map would have looked like in Bidibidi, if a RGWPM would have been available upon onset of the drilling campaigns during the early emergency phase.

In the humanitarian context, staff turnover is high which can result in low institutional memory and data loss. To mitigate this issue, UNHCR and its partners have developed an online database (UNHCR 2021b). Loss of data may be one reason for the failure to get high-yielding boreholes prior to the use of RGWPM, but another reason may also be related to the lack of a common borehole siting strategy. Whatever the reason may be, the boreholes' yields are eventually translated into water production figures for refugees, which in turn are reported as indicators (minimum standard of $20 \mathrm{~L}$ per person per day). Hence, if wells are not adequately sited and exploited, as suggested by the aforementioned simple analysis, the derived indicators will call for additional funds to fill any gaps in the water demand. In that respect, the results obtained from the boreholes sited with the RGWPM are highly encouraging. Moreover, the boreholes sited with the RGWPM can also support the trend in the humanitarian context towards solarisation/motorization, suggesting that it is possible to move away from the classic hand pump water supply scheme.

\section{Conclusion}

The main objective of this work was to support humanitarian efforts to site boreholes more efficiently using a methodology called Rapid Groundwater Potential Mapping (RGWPM). RGWPM is in line with the humanitarian needs during emergencies, being rapid, providing humanitarian agencies with a practical tool within days or weeks. It is also in alignment with the increasing trend towards solarisation of boreholes, which commonly requires higher yields than what hand pumps need. The mapping done in a few days delimits the groundwater potential zones and informs water supply options. The RGWPM methodology cannot be fully automated and requires an experienced hydrogeologist to be implemented. The results can be shared with site planers to allow them to factor in borehole siting with overall site plans taking into account demographical and socio-economic factors.
The groundwater potential zones of RGWPM were obtained from the spatial overlay of the WA and RC, with the lower of the two variables determining the GWP. The WA is better defined and more quickly mapped, thus limiting the area where the RC is evaluated to areas with a medium WA or high WA. The WA mapping criteria are based on a simplistic but physically grounded transposition of the conceptual framework of Winter (2001) hydrological landscape units into hydrogeological processes by the identification of geomorphological features. The RC overlay expresses the geological features as hydraulic conductivities.

The Ugandan case study results showed that although there is a degree of uncertainty related to the mapped variables, the mapped units and the groundwater potential zones based on physical processes increase success rates as opposed to alternative borehole siting strategies used by humanitarian agencies (e.g. siting based on demographic criteria). The crossvalidation on the Northern Ugandan refugee settlement of Bidibidi highlights that the eight boreholes sited with RGWPM extract more than 92 existing boreholes, with average yields of $35 \mathrm{~m}^{3} / \mathrm{h}$ as compared to $3 \mathrm{~m}^{3} / \mathrm{h}$ for boreholes sited without RGWPM. The semiquantification of RGWPM reveals that the medium groundwater potential zones correlate with motorised systems and the low and slope zones with hand pumps.

Rapid Groundwater Potential Mapping has so far only been applied to the fractured aquifer systems In Bidibidi, in a humid to semiarid region, where the landscape dominantly results from erosional processes linked to water. There are a number of limitations to RGWPM, with the highest uncertainty related to the mapping process of the reservoir capacity. Another limitation is that complex geological settings such as multilayered systems, cannot be addressed with this methodology. Finally, these maps do not consider existing boreholes; hence, implementing numerous boreholes within the same medium or high groundwater potential zone will always have to be associated with considerations on the sustainability of the exploitation.

The authors fully acknowledge that considering groundwater recharge and hydraulic conductivities through hydrogeomorphological classification, as done in this work, is an extremely simplified approach. Nevertheless, during acute emergencies when crucial decisions are being made which have considerable financial and operation implications, RGWPM has the potential to foster more successful geophysical and subsequent drilling campaigns. Also, it is believed that RGWPM has the future potential for establishing a common framework or approach for groundwater exploration in humanitarian situations. Since only one RGWPM map needs to be established for one area, it could even be used as a coordination tool, allowing different humanitarian actors in water supply to join efforts using a common (physically based) approach. 
Acknowledgements We thank the United Nations High Commissioner for Refugees (UNHCR) for providing logistical support and security during field missions as well as access to numerous data related to water supply in Bidibidi. Finally, we would also like to thank the reviewers for their constructive and fruitful comments.

Funding Open Access funding provided by University of Neuchâtel. Our gratitude goes to the Humanitarian Aid Unit of the Swiss Agency for Development and Cooperation (SDC) for the grant 7F-09881.01.09 which allowed the implementation and documentation of the RGWPM approach.

\section{Declarations}

Conflict of interests We declare that we have no personal interests in the development of the RGWPM approach and no conflict of interests related to this publication.

Open Access This article is licensed under a Creative Commons Attribution 4.0 International License, which permits use, sharing, adaptation, distribution and reproduction in any medium or format, as long as you give appropriate credit to the original author(s) and the source, provide a link to the Creative Commons licence, and indicate if changes were made. The images or other third party material in this article are included in the article's Creative Commons licence, unless indicated otherwise in a credit line to the material. If material is not included in the article's Creative Commons licence and your intended use is not permitted by statutory regulation or exceeds the permitted use, you will need to obtain permission directly from the copyright holder. To view a copy of this licence, visit http://creativecommons.org/licenses/by/4.0/.

\section{References}

Abdalla F (2012) Mapping of groundwater prospective zones using remote sensing and GIS techniques: a case study from the central Eastern Desert, Egypt. J Afr Earth Sci 70:8-17

Beck HE, Zimmermann NE, McVicar TR, Vergopolan N, Berg A, Wood EF (2018) Present and future Köppen-Geiger climate classification maps at 1-km resolution. Scientific Data 5:180214

Bense VF, Gleeson T, Loveless SE, Bour O, Scibek J (2013) Fault zone hydrogeology. Earth Sci Rev 127:171-192

Chilton PJ, Foster SSD (1995) Hydrogeological characterisation and water-supply potential of basement aquifers in tropical Africa. Hydrogeol J 3(1):36-49

Chorley RJ, Schumm SA, Sugden DE (1984) Geomorphology. Methuen, London

Dept of Geological Survey and Mines of Uganda (DGSM) (2004) 1:2 Million scale geology map of Uganda

Dewandel B, Lachassagne P, Wyns R, Maréchal JC, Krishnamurthy NS (2006) A generalized 3-D geological and hydrogeological conceptual model of granite aquifers controlled by single or multiphase weathering. J Hydrol 330(1-2):260-284

Díaz-Alcaide S, Martínez-Santos P (2019) Advances in groundwater potential mapping. Hydrogeol J 27(7):2307-2324

Domenico PA, Schwartz FW (1990) Physical and chemical hydrogeology. Wiley, New York, 824 pp

Dupuit J (1857) Mouvement de l'eau à travers les terrains perméables [Movement of water through permeable terrain]. CR Hebd Seances Acad Sci 45:92-96

Dupuit J (1863) Études théoriques et pratiques sur le mouvement des eaux dans les canaux découverts et à travers les terrains perméables: avec des considérations relatives au régime des grandes eaux, au débouché à leur donner, et à la marche des alluvions dans les rivières à fond mobile [Theoretical and practical studies on the movement of water in open canals and through permeable soils: with considerations relating to the regime of large waters, the outlet to be given to them, and the progress of alluvium in rivers with movable bottoms]. Dunod, Paris

Elewa HH, Qaddah AA (2011) Groundwater potentiality mapping in the Sinai Peninsula, Egypt, using remote sensing and GIS-watershedbased modeling. Hydrogeol J 19(3):613-628

Ettazarini S (2007) Groundwater potentiality index: a strategically conceived tool for water research in fractured aquifers. Environ Geol 52(3):477-487

Evans JP, Forster CB, Goddard JV (1997) Permeability of fault-related rocks, and implications for hydraulic structure of fault zones. J Struct Geol 19(11):1393-1404

Forchheimer P (1986) Uber die Ergiebigkeit von Brunnen, Anlagen und Sickerschlitzen [About the yield of wells, systems and seepage trenches], vol 32. Z. Archit. Ing., Hannover, Germany, pp 539-563

Freeze RA, Witherspoon PA (1967) Theoretical analysis of regional groundwater flow: 2. effect of water-table configuration and subsurface permeability variation. Water Resour Res 3(2):623-634

Freeze RA, Cherry JA (1979) Groundwater. Prentice-Hall, Englewood, Cliffs, New Jersey, p 604

Haitjema HM, Mitchell-Bruke S (2005) Are water tables a subdued replica of the topography? Groundwater 43(6):781-786

Heath RC (1984) ground-water regions of the United States, vol 2242. US Geological Survey, Reston, VA

Horton RE (1945) Erosional development of streams and their drainage basins: hydrophysical approach to quantitative morphology. Geol Soc Am Bull 56(3):275-370

Houston J (1992) Rural water supplies: comparative case histories from Nigeria and Zimbabwe. Geol Soc Lond Spec Publ 66(1):243-257

Hutton G, Haller L, Water S (2004) Evaluation of the costs and benefits of water and sanitation improvements at the global level. No. WHO/ SDE/WSH/04.04, World Health Organization, Geneva

Kyatengerwa C, Kim D, Choi M (2020) A national-scale drought assessment in Uganda based on evapotranspiration deficits from the Bouchet hypothesis. J Hydrol 580:124348

Leopold LB, Wolman MG, Miller JP (1964) Fluvial processes in geomorphology. Freeman, San Francisco, 522 pp

Mandal U, Sahoo S, Munusamy SB, Dhar A, Panda SN, Kar A, Mishra PK (2016) Delineation of groundwater potential zones of coastal groundwater basin using multi-criteria decision making technique. Water Resour Manag 30(12):4293-4310

Meinzer OE (1923) The occurrence of ground water in the United States with a discussion of principles, vol 50, no. 846. University of Chicago, Chicago, IL

Purcell PG (2018) Re-imagining and re-imaging the development of the East African Rift. Petroleum Geoscience 24:21-40. https://doi.org/ 10.1144/petgeo2017-036

Scheidegger AE (1973) Hydrogeomorphology. J Hydrol 20(3):193-215

Sidle RC, Onda Y (2004) Hydrogeomorphology: overview of an emerging science. Hydrol Process 18(4):597-602

Sikakwe GU (2020) Geospatial applications in delineating groundwater prospect zones in a hard rock terrain: an integrated approach. Environ Earth Sci 79(21):1-18

Taylor R, Howard K (2000) A tectono-geomorphic model of the hydrogeology of deeply weathered crystalline rock: evidence from Uganda. Hydrogeol J 8(3):279-294

Teixeira J, Chaminé HI, Marques JE, Carvalho JM, Pereira AJSC, Carvalho MR, Fonseca PE, Pérez-Alberti A, Rocha F (2015) A comprehensive analysis of groundwater resources using GIS and multicriteria tools (Caldas da Cavaca, Central Portugal): environmental issues. Environ Earth Sci 73(6):2699-2715 
Thiéblemont D, Liégeois JP, Fernandez-Alonso M, Ouabadi A, Le Gall B, Maury R, Michard A (2016) Geological map of Africa at 1:10M scale. Geological map, CGMW-BRGM, Orléans, France

Toth J (1963) A theoretical analysis of groundwater flow in small drainage basins. J Geophys Res 68(16):4795-4812

UNHCR (2017a) WASH Uganda: WASH situational and gap analysis. https://data2.unhcr.org/en/documents/details/63327. Accessed August 27, 2020

UNHCR (2017b) UGA factsheet Bidibidi gap analysis. https://data2. unhcr.org/en/documents/details/6496. Accessed August 27, 2020

UNHCR (2020) Global trends in forced displacement. https://www. unhcr.org/statistics/unhcrstats/5ee200e37/unhcr-global-trends2019.html. Accessed August 27, 2020

UNHCR (2021a) Clean energy challenge. The UN Refugee Agency. https://www.unhcr.org/clean-energy-challenge.html. Accessed March 2021

UNHCR (2021b) WASH GIS portal. http://wash.unhcr.org/wash-gisportal/. Accessed March 29, 2021
Winter TC (2001) The concept of hydrologic landscapes 1. JAWRA J Am Water Resour Assoc 37(2):335-349

Wright EP (1992) The hydrogeology of crystalline basement aquifers in Africa. Geol Soc Lond Spec Publ 66(1):1-27

Wyns R, Dewandel B, Lachassagne P (2015) Origine de la fracturation des aquifères de socle: quels sont les facteurs qui contrôlent les propriétés de l'horizon fissuré? Origin of fracturation in hard-rock aquifers: what are the factors that control the properties of the fissured horizon. 20th holding of the Technical Days of the International Association of Hydrogeologists French Chapter, Vendee, France, June 2015

WWAP (UNESCO World Water Assessment Programme) (2019) The United Nations World Water Development Report 2019: Leaving No One Behind. UNESCO, Paris

Publisher's note Springer Nature remains neutral with regard to jurisdictional claims in published maps and institutional affiliations. 